\title{
COMPUTATION OF LONGSHORE CURRENTS AND SEDIMENT TRANSPORT
}

\author{
Fernando J. Caviglia* \\ Comisión de Investigaciones Científicas de la Provincia de Buenos Aires y Facultad de Ciencias \\ Naturales y Museo, UNLP, Casilla de Correo 45 (1900) La Plata, Argentina
}

(Received 26 July 1993; accepted 28 December 1993)

\begin{abstract}
A numerical model for the steady-state profile of the longshore current induced by regular, obliquely incident, breaking waves is presented. The wave parameters must be given at an arbitrary depth. A rapid convergent numerical algorithm is described for the solution of the governing equation. The model is solved using a nonlinear bottom friction law in which the friction coefficients are a function of the bottom roughness which is computed at each point using an empirical formula. The predicted current profiles are combined with some of the known formulae for sediment transport computations.
\end{abstract}

Key Words: Longshore currents, Sediment transport, Numerical model, Forward sweep implicit technique.

\section{INTRODUCTION}

If breaking waves approach a straight coastline at an oblique angle, they induce a longshore current in the surf zone. The current acts somewhat analogous to a river, transporting sediment mobilized by the breaking waves, and is confined to a zone with a width of two to three times the width of the surf zone. The prediction of such longshore currents and the associated sediment transport is of prime importance for coastal engineers.

The purpose of this paper is to present a numerical model of longshore current in combination with some of the known formulae for predicting sediment transport which can be used for engineering purposes. The model is solved on a desktop computer and requires only data available in any engineering project.

\section{LONGSHORE CURRENT MODEL}

According to the generally employed assumptions in longshore current modeling, namely (i) longshore uniformity in waves and bottom topography, (ii) negligible bottom friction in the cross-shore direction, and (iii) applicability of linear-wave theory, the vertically integrated, time-averaged momentum equations for nearshore water motion (Mei, 1983) become

$$
\begin{gathered}
\rho g d \frac{\mathrm{d} \eta}{\mathrm{d} x}=-\frac{\mathrm{d} S_{x x}}{\mathrm{~d} x}, \\
\frac{\mathrm{d}}{\mathrm{d} x}\left[A_{\mathrm{h}} d \frac{\mathrm{d} V}{\mathrm{~d} x}\right]-\frac{\tau_{\mathrm{b} y}}{\rho}=\frac{1}{\rho} \frac{\mathrm{d} S_{x y}}{\mathrm{~d} x},
\end{gathered}
$$

*Address for correspondence: Laboratorio de Oceangrafia Costera y Estuarios, Casilla de Correo 45 (1900) La Plata, Argentina. for the cross-shore $x$ component and for the longshore $y$ component respectively (see Fig. 1), where $\rho$ is the water density, $g$ the acceleration resulting from gravity, $d=h+\eta$ the mean water depth, $h$ the still water depth, $\eta$ the elevation of the free surface above the still water level, $A_{\mathrm{h}}$ the eddy viscosity coefficient, $V$ the longshore current velocity and $\tau_{b y}$ the bottom frictional stress. The radiation stress components $S_{x x}$ and $S_{x y}$ are given by

$$
\begin{gathered}
S_{x x}=E\left[n\left(\cos ^{2} \alpha+1\right)-\frac{1}{2}\right], \\
S_{x y}=\frac{\sin \alpha}{C} F_{x},
\end{gathered}
$$

where $F_{x}=-E C n \cos \alpha$ is the wave energy flux towards the shoreline, $C$ the phase velocity of waves, $n=\frac{1}{2}+(k d / S h 2 k d), \alpha$ the angle that the wave front makes with the shoreline, $E=\frac{1}{8} \rho g H^{2}$ the energy density of the waves per unit area, $H$ the wave height, $k=2 \pi / L$ the wave number and $L$ the wavelength. The phase velocity is calculated with the approximated expression introduced by Visser (1984)

$$
C=\left\{\begin{array}{ll}
\sqrt{g d}\left(1-\frac{d}{L_{0}}\right) & \text { as } \frac{d}{L_{0}} \leqslant 0.36 \\
\frac{g T}{2 \pi}=C_{0} & \text { as } \frac{d}{L_{0}}>0.36
\end{array},\right.
$$

where $T$ is the wave period and the subscript 0 denotes a value on deep water.

\section{Wave set-up}

Equation (1) governs the mean water surface displacement $\eta$. According to the specific assumptions of this paper namely, (iv) constant beach slope, (v) 
proportionality between the wave height and the mean water depth in the surf zone, $H=\gamma d$, (vi) negligible wave set-down offshore of the plunge line, $x_{\mathrm{p}}$, and (vii) applicability of the shallow water approximation, $n=1, \cos \alpha \cong 1$ and $C=\sqrt{g d}$, the equation for the mean water surface displacement can be integrated to obtain

$$
\eta=K s\left(x_{\mathrm{p}}-x\right),
$$

where $K=\left[1+8 / 3 \gamma^{2}\right]^{-1}, \gamma$ the breaker index and $s$ the beach slope. If Equation (6) is evaluated at $x=x_{s}$, the following relation can be obtained

$$
x_{\mathrm{s}}=K x_{\mathrm{p}},
$$

where $x_{\mathrm{s}}$ is the line of maximum wave set-up. The plunge line is calculated with the following expression (Svendsen, 1987; Larson and Kraus, 1989)

$$
x_{\mathrm{p}}=x_{\mathrm{b}}-3 H_{\mathrm{b}},
$$
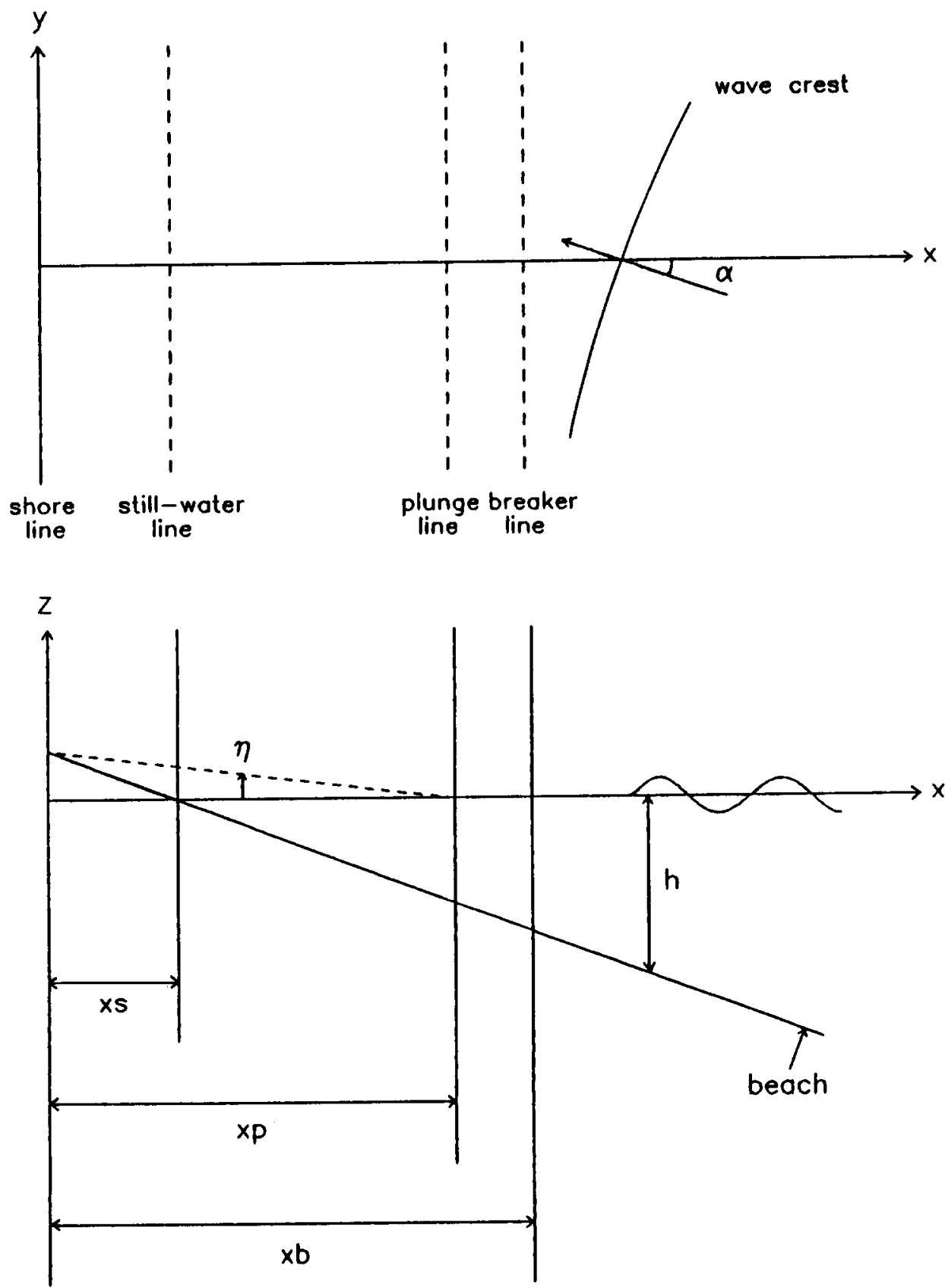

Figure 1. Definition sketch for coordinate system and nearshore region, where $\eta$ is wave set-up, $h$ still-water depth, $x_{\mathrm{b}}$ width of breaker zone, $x_{\mathrm{s}}$ distance from shoreline to still-water line, $x_{\mathrm{p}}$ distance from shoreline to plunge line, and $\alpha$ angle of incidence of waves. 
the breaker zone width and $d_{\mathrm{b}}$ the depth at breaking $\left(d_{\mathrm{b}}=H_{\mathrm{b}} / \gamma\right)$.

Substitution of (8) into (7), taking into account the expression for $x_{\mathrm{b}}$, gives

$$
x_{\mathrm{s}}=\frac{3 \gamma^{2}}{8}\left[\frac{d_{\mathrm{b}}}{\mathrm{s}}-3 H_{\mathrm{b}}\right] .
$$

From (6) and (7), the mean water depth can be written as

$$
d=\left\{\begin{array}{ccc}
\left(1-\frac{\bar{x}_{\mathrm{s}}}{P}\right) \mathrm{s} \bar{x} \frac{x_{\mathrm{b}}}{d_{\mathrm{b}}} & \text { as } & \bar{x} \leqslant P \\
\left(\bar{x}-\bar{x}_{\mathrm{s}}\right) \mathrm{s} \frac{x_{\mathrm{b}}}{\mathrm{d}_{\mathrm{b}}} & \text { as } & \bar{x}>P
\end{array},\right.
$$

where the following dimensionless variables were introduced

$$
a=\frac{d}{d_{\mathrm{b}}}, \quad \bar{x}=\frac{x}{x_{\mathrm{b}}}, \quad P=\frac{x_{\mathrm{p}}}{x_{\mathrm{b}}}, \quad \bar{x}_{\mathrm{s}}=\frac{x_{\mathrm{s}}}{x_{\mathrm{b}}} .
$$

\section{Driving force}

The longshore driving force resulting from obliquely incident wave is

$$
\frac{\partial S_{x y}}{\partial x}=\frac{\sin \alpha_{i}}{C_{i}} \frac{\partial F_{x}}{\partial x}
$$

where the subscript $i$ denotes a value at an arbitrary depth.

Substituting the expressions of the wave energy flux towards the shoreline and the energy density of the waves per unit area, in combination with the assumption (v) and the shallow water approximation, into (12) gives

$$
\frac{\partial S_{x y}}{\partial x}=\frac{\sin x_{i}}{C_{i}}\left\{\begin{array}{ll}
-\frac{5}{16} \rho g^{3 / 2} \gamma^{2}\left[\frac{d_{\mathrm{b}}}{x_{\mathrm{b}}}\right]^{5 / 2} x^{3 / 2} & \text { as } x \leqslant x_{\mathrm{b}} \\
0 & \text { as } x>x_{\mathrm{b}}
\end{array} .\right.
$$

Visser (1984) introduced the following assumptions: (viii) the dissipation of wave energy takes place shoreward of the plunge line, (ix) $\mathrm{d} F_{x} / \mathrm{d} x$ is proportional to $x^{3 / 2}$ shoreward of the plunge line and vanishes offshore of this line, and ( $x$ ) the transport of wave energy towards the shore is given by the transport of wave energy predicted by linear wave theory in the cross-shore $x$-direction. Under these assumptions follows from Equation (13) that

$$
\frac{\partial S_{x y}}{\partial x}=\frac{\sin \alpha_{i}}{C_{i}}\left\{\begin{array}{lll}
-D_{\mathrm{b}}\left[\frac{\bar{x}}{P}\right]^{3 / 2} & \text { as } & \bar{x} \leqslant P \\
0 & \text { as } & \bar{x}>P
\end{array},\right.
$$

where

$$
D_{\mathrm{b}}=\frac{5}{2} \frac{1}{P x_{\mathrm{b}}} E_{i} C_{i} n_{i} \cos \alpha_{i}
$$

\section{Bottom friction term}

Under the combined action of waves and currents the time-averaged bottom friction in longshore direction can be expressed as

$$
\begin{aligned}
\frac{\tau_{\text {by }}}{\rho}= & \frac{1}{8} F \frac{1}{T} \int_{0}^{T}\left[V^{2}+2 \xi u_{\mathrm{m}} V \sin \alpha \cos \omega t\right. \\
& \left.+\left(\xi u_{\mathrm{m}}\right)^{2} \cos ^{2} \omega t\right]^{1 / 2} \\
& *\left(V+\xi u_{\mathrm{m}} \sin \alpha \cos \omega t\right) \mathrm{d} t,
\end{aligned}
$$

where $\omega=2 \pi / T$ is the angular frequency, $u_{\mathrm{m}}=\pi / T$ $H / S h k d$ the maximum orbital velocity near the bottom and $\xi=2\left(F_{\mathrm{w}} / F\right)^{1 / 2}$ with $F_{\mathrm{w}}$ being the Jonsson friction coefficient and $F$ the Darcy-Weisbach friction coefficient.

Because the elliptic integral (15) must be solved frequently in the numerical longshore current program in this paper the square wave approximation introduced by Nishimura (1988) is used. Then, the time-averaged bottom friction in longshore direction becomes

$$
\begin{gathered}
\frac{\tau_{\text {by }}}{\rho}=\frac{1}{8} F\left(Z+\frac{z^{2} \sin ^{2} \alpha}{Z}\right) V \\
Z=\frac{1}{2}\left[\left(V^{2}+z^{2}+2 z V \sin \alpha\right)^{1 / 2}\right. \\
\left.+\left(V^{2}+z^{2}-2 z V \sin \alpha\right)^{1 / 2}\right] .
\end{gathered}
$$

and $z=(2 / \pi) \xi u_{\mathrm{m}}$.

The most popular formulae for predicting the friction coefficients are

$$
\begin{gathered}
F_{\mathrm{w}}=\left\{\begin{array}{l}
\exp \left[-5.977+5.213\left(\frac{r}{a_{\mathrm{b}}}\right)^{0.194}\right] \\
0.3 \quad \text { as } \frac{r}{a_{\mathrm{b}}} \leqslant 0.63
\end{array}\right. \\
F=8\left[2.5 \ln \frac{12 d}{r}\right]^{-2}
\end{gathered}
$$

where $a_{\mathrm{b}}=u_{\mathrm{m}} / \omega$ is the horizontal water particle excursion at the bottom and $r$ the equivalent diameter of the roughness elements. Equation (17) was suggested by Jonsson (1980) and Equation (18) is based on Nikuradse's experiments. According to Nielsen (1985) the total roughness, $r$, is calculated from the following expression

$$
r=190 D \sqrt{\theta^{\prime}-0.05}+8 \frac{\eta_{r}^{2}}{\lambda_{\mathrm{r}}},
$$

where $\eta_{\mathrm{r}}$ is the ripple height, $\lambda_{\mathrm{r}}$ the ripple length, $D$ the mean sediment grain diameter, $\theta^{\prime}=\frac{1}{2} F_{w}^{\prime} \Psi$ the so-called skin friction Shields parameter, $F_{w}^{\prime}$ the Jonsson friction coefficient based on $r=2.5 D, \Psi=u_{\mathrm{m}}^{2} /[(s-1) g D]$ the mobility parameter and $s$ the relative sediment density $\left(s=\rho_{\mathrm{s}} / \rho\right.$, where $\rho_{\mathrm{s}}$ is the sediment density). If $\theta^{\prime} \leqslant 0.05$ then $r=2.5 D$, which is the roughness for a flatbed of fixed sand 
grains. Nielsen (1981) recommended the following formulae for prediction of ripple geometry

$$
\begin{gathered}
\frac{\eta_{\mathrm{r}}}{\lambda_{\mathrm{r}}}=0.342-0.34 \sqrt[4]{\theta^{\prime}}, \\
\frac{\eta_{\mathrm{r}}}{a_{\mathrm{b}}}= \begin{cases}0.275-0.022 \sqrt{\Psi} & \text { as } \Psi \leqslant 10 \\
21 \Psi^{-1.85} & \text { as } \Psi \geqslant 10^{\circ}\end{cases}
\end{gathered}
$$

This author recommended to base the ripple calculations on the significant wave height for field situations.

The proposed expressions for ripple geometry calculation are valid for nonbreaking wave conditions. Ripples are washed out when the mobility parameter, $\Psi$, is larger than about 200-250 (see Dingler and Inman, 1976). Van Rijn (1989) assumed that the ripple existence is limited to values of $\Psi$ smaller than 250 . Then, from Equation (19)

$$
r=190 D \sqrt{\theta^{\prime}-0.05},
$$

which is the formula recommended by Nielsen (1985) for the prediction of the roughness of flat, mobile sand beds. Under breaking wave conditions the mobility parameter, in general, will be larger than 250 . Furthermore, it is assumed that the longshore current has no influence upon the ripple geometry.

\section{Lateral mixing}

The first term of Equation (2) is an empirical closure relation describing lateral mixing resulting from Reynolds stresses. Visser (1984) expressed the eddy viscosity coefficient as

$$
A_{\mathrm{h}}=\mathrm{M} q d,
$$

where $\mathbf{M}$ is a constant of order 3 and $q$ the characteristic turbulent velocity. The nondimensional form of $A_{\mathrm{h}}$ is

$$
\overline{A_{\mathrm{h}}}=\frac{A_{\mathrm{h}}}{A_{0}},
$$

where $A_{0}$ can be defined in arbitrary form.

The eddy viscosity coefficient resulting from this parameterization decreases rapidly offshore of the plunge line. This result seems to be in agreement with the laboratory measurements of Deguchi, Sawaragi, and Ono (1992), who determined that $A_{\mathrm{h}}$ becomes maximum near $d / d_{\mathrm{b}}=0.7-0.8$ and decreases rapidly toward offshore.

\section{NUMERICAL SOLUTION}

Substitution of (14), (16), and (24) into (2) yields

$$
\frac{\mathrm{d}^{2} \bar{V}}{\mathrm{~d} \bar{x}^{2}}+g_{1}(\bar{x}) \frac{\mathrm{d} \bar{V}}{\mathrm{~d} \bar{x}}-g_{2}(\bar{x}) \bar{V}=\left\{\begin{array}{lll}
-g_{3}(\bar{x}) & \text { as } & \bar{x} \leqslant P \\
0 & \text { as } & \bar{x}>P
\end{array},\right.
$$

in which $\bar{V}=V / V_{0}$,

$$
g_{1}(\bar{x})=\frac{1}{\bar{A}_{\mathrm{h}} \bar{\partial}} \frac{\mathrm{d} \bar{A}_{\mathrm{h}} \overline{\mathrm{d}} \bar{x}}{,}
$$

$$
\begin{gathered}
g_{2}(\bar{x})=C_{1} \frac{F\left(Z+\frac{z^{2} \sin ^{2} \alpha}{Z}\right)}{\bar{A}_{\mathrm{h}} \bar{d}}, \\
\boldsymbol{g}_{3}(\bar{x})=\frac{1}{\bar{A}_{\mathrm{h}} \bar{d}}[\overline{\bar{x}} \bar{P}]^{3 / 2},
\end{gathered}
$$

with

$$
C_{1}=\frac{1}{8} \frac{x_{\mathrm{b}}^{2}}{A_{0} d_{\mathrm{b}}} \quad \text { and } \quad V_{0}=\frac{D_{\mathrm{b}} x_{\mathrm{b}}^{2}}{\rho A_{0} d_{\mathrm{b}}} \frac{\sin \alpha_{i}}{C_{i}} .
$$

The differential equation to be solved is nonlinear because $g_{2}(\bar{x})$ contains $V$ through $Z$. The differential equation is solved as a linear equation. This is done by solving (25) and (27) with an iteration procedure. The canonical form of the differential equation for (25) for calculation of the grid cell number is

$$
\begin{gathered}
\boldsymbol{g}_{\mathbf{4}_{i}} \overline{\boldsymbol{V}}_{i-1}+\boldsymbol{g}_{5_{i}} \bar{V}_{i}+\boldsymbol{g}_{6_{i}} \bar{V}_{i+1}=\boldsymbol{g}_{7_{i}}, \\
\boldsymbol{g}_{4_{i}}=1-\frac{1}{2} \boldsymbol{g}_{1_{i}} \Delta \bar{x}, \quad \boldsymbol{g}_{5_{i}}=-\left(2+\boldsymbol{g}_{2_{i}} \Delta \bar{x}^{2}\right) \\
\boldsymbol{g}_{6_{i}}=1+\frac{1}{2} \boldsymbol{g}_{1_{i}} \Delta \bar{x}
\end{gathered}
$$

and

$$
\boldsymbol{g}_{7_{i}}=\left\{\begin{array}{lll}
-\boldsymbol{g}_{3_{i}} \Delta \bar{x}^{2} & \text { as } & \bar{x} \leqslant P \\
0 & \text { as } & \bar{x}>P
\end{array} .\right.
$$

Equation (29) is solved for each calculation cell with $i$ extending from 2 to $N-1$, for a grid encompassing $N$ cells. Boundary conditions for $\bar{V}$ must be provided at cells 1 and $N$. The boundary conditions are

$$
\begin{array}{lllll}
\bar{V}=0 & \text { as } & \bar{x}=0 & \text { or } & i=1 \\
\bar{V}=0 & \text { as } & \bar{x} \rightarrow \infty & \text { or } & i \rightarrow \infty
\end{array}
$$

with $\bar{x}=(i-1) \Delta \bar{x}$.

Because for $\bar{x}>2$ the longshore current velocity $\bar{V}$ becomes small (Visser, 1984) it is assumed that

$$
\bar{V}=0 \quad \text { as } \quad \bar{x}=3 \text { or } i=241
$$

if $\Delta \bar{x}=1 / 80$.

For $i=2-240$, Equation (29) is a tridiagonal set of linear equations in the unknowns $V=\left[\bar{V}_{2}\right.$, $\left.\bar{\nabla}_{3}, \ldots, \bar{V}_{N-1}\right]$ and can be written in matrix form as $\mathbb{M V}=\mathbb{G}$ where $\mathbb{G}=\left[\boldsymbol{g}_{7_{2}}, \boldsymbol{g}_{7_{3}}, \ldots, \boldsymbol{g}_{7_{N-1}}\right]$. The matrix $M$ is tridiagonal with principal diagonal elements $\boldsymbol{g}_{5_{i}}$, the elements to left of the diagonal are $g_{4}$ and to the right are $\boldsymbol{g}_{\boldsymbol{\sigma}_{i}}$. All the other elements are zero. This system is solved easily by forward sweep and a backward substitution. The algorithm is simply Gaussian elimination. The backward substitution solves for $\bar{V}$, and it is given by

$$
\bar{V}_{i}=U_{i}-W_{i} \bar{V}_{i+1} \text { for } i=2-240,
$$

where

$$
\begin{aligned}
W_{i} & =\frac{\boldsymbol{g}_{6 i}}{\boldsymbol{g}_{5_{i}}-W_{i-1} \boldsymbol{g}_{4_{i}}} \text { and } U_{i} \\
& =\frac{\boldsymbol{g}_{7_{i}}-U_{i-1} \boldsymbol{g}_{\mathbf{4}_{i}}}{\boldsymbol{g}_{5_{i}}-W_{i-1} \boldsymbol{g}_{4_{i}}}
\end{aligned}
$$

with

$$
\nabla_{241}=W_{1}=U_{1}=0 \text {. }
$$


Table 1. Limiting wave height (from Van Rijn, 1989)

\begin{tabular}{rccc}
\hline & \multicolumn{3}{c}{ Breaker index } \\
\cline { 2 - 4 } Wave steepness & $\mathrm{s}=1 / 100$ & $\mathrm{~s}=1 / 20$ & $\mathrm{~s}=1 / 10$ \\
\hline$H_{\mathrm{s} .} / L_{0}=0.002$ & 0.60 & 0.70 & 0.80 \\
0.004 & 0.60 & 0.70 & 0.80 \\
0.006 & 0.60 & 0.70 & 0.80 \\
0.010 & 0.60 & 0.70 & 0.80 \\
0.020 & 0.50 & 0.65 & 0.80 \\
0.040 & 0.40 & 0.55 & 0.70 \\
0.060 & 0.35 & 0.50 & 0.70 \\
\hline
\end{tabular}

The forward sweep reduces $M$ to an upper-triangular matrix with principal diagonal elements unity and elements to the right of the diagonal given by $W_{i}$. The current velocity calculated with (30), previously multiplied by $V_{0}$, is replaced into (27) and the procedure described here is repeated again. This procedure is carried out until the absolute value of the difference between $\bar{V}_{i}$ and the velocity calculated in the preceding iteration step be less than $\epsilon=0.01$. In general, the solution converges after no more than eight iterations.

\section{FIELD SITUATIONS}

A question which arises in comparing monochromatic wave models with field random waves is the determination of an appropriate wave height parameter for model calculations. $\mathrm{Wu}$, Thornton, and Guza (1985) gave a detailed explanation for selecting the root-mean square wave height, $H_{\mathrm{r} \text {.m.s. }}$, as the appropriate one.

Another related problem is the appropriate breaker index for random waves. Thornton, $\mathrm{Wu}$, and Guza (1984) presented a criteria for random breaking waves based on field and laboratory data. From their results, Van Rijn (1989) derived the values of $\gamma_{s}\left(\gamma_{\mathrm{s}}=H_{\mathrm{bs}} / d_{\mathrm{b}}\right.$, where $H_{b s}$ is the significant breaking wave height) shown in Table 1. Multiple linear regression gives

$$
\gamma_{\mathrm{s}}=0.603+2.147 \mathrm{~s}+(30.685 \mathrm{~s}-5.192)\left[\frac{H_{0 \mathrm{~s}}}{L_{0}}\right] .
$$

where the correlation coefficient is 0.99 .

For a Rayleigh wave height probability distribution, the relationship between significant wave height and root-mean square wave height is $H_{\mathrm{s}} \cong \sqrt{2} H_{\text {r.m.s. }}$. Thornton, $\mathrm{Wu}$, and Guza (1984) showed that this relation could be used with an error of about $\pm 5 \%$. From this relation, it is assumed that

$$
\gamma_{\text {r.m.s. }}=\gamma_{s} / \sqrt{2}
$$

where $\gamma_{\text {r.m.s. }}$ is the breaker index based on $H_{\text {r.m.s. }}$.

When the input conditions are those at the breaker line a simple predictive formula is used to estimate the deep water wave height prior to determining the breaker index (Larson and Kraus, 1989)

$$
H_{\text {bs }}=0.53 H_{0 \mathrm{~s}}\left[\frac{H_{0 \mathrm{~s}}}{L_{0}}\right]^{-0.24} \text {. }
$$

\section{USING THE MODEL}

The program has been written in Microsoft QuickBASIC 4.50. The user is requested to input the following parameters: the significant wave height $\left(H_{\mathrm{s}}\right.$ in meters) or the root-mean square wave height $\left(H_{\text {r.m.s. }}\right.$ in meters), the angle that the wave front makes with the shoreline ( $\alpha$ in degrees), the wave period ( $T$ in seconds), the depth in which wave measurements were made (meters) if the wave conditions are not at the breaker line, the beach slope, the mean sediment diameter ( $D$ in millimeters $)$, the particle diameter $D_{90}(10 \%$ by weight exceeded in size, millimeters) which is not strictly necessary for the program to be run, and the sediment density ( $\rho_{\mathrm{s}}$ in kilogram per cubic meter). With these parameters the program computes the longshore current and sediment transport distributions, the mean longshore current in $\mathrm{m} / \mathrm{s}$ and the longshore sediment transport rate in $\mathrm{m}^{3} / \mathrm{s}$ and $\mathrm{m}^{3} /$ day.

The program includes a routine which allows a screen view of the longshore current and sediment transport distributions. This routine requires a VGA or MCGA display adapter.

As an example of the program capability a print screen of the resulting longshore current distribution for the Thornton and Guza (1986, 1989) 4 February data are shown in Figure 2. Wave conditions at $9.1-\mathrm{m}$ depth were: $H_{\text {r.m.s. }}=0.52 \mathrm{~m}, T=14.2 \mathrm{sec}$ and $\alpha=18.4^{\circ}$, with $\mathrm{s}=0.038, D=0.23 \mathrm{~mm}$ (Gable, 1981) and $\rho_{\mathrm{s}}=2650 \mathrm{~kg} / \mathrm{m}^{3}$. The data are superimposed on the graph.

\section{DISCUSSION}

The specialized problem of studying longshore current generation in the surf zone is solved by the use of a forward sweep implicit technique. The program presented here is short, fast, easy to use, and versatile. The numerical model can be adapted easily

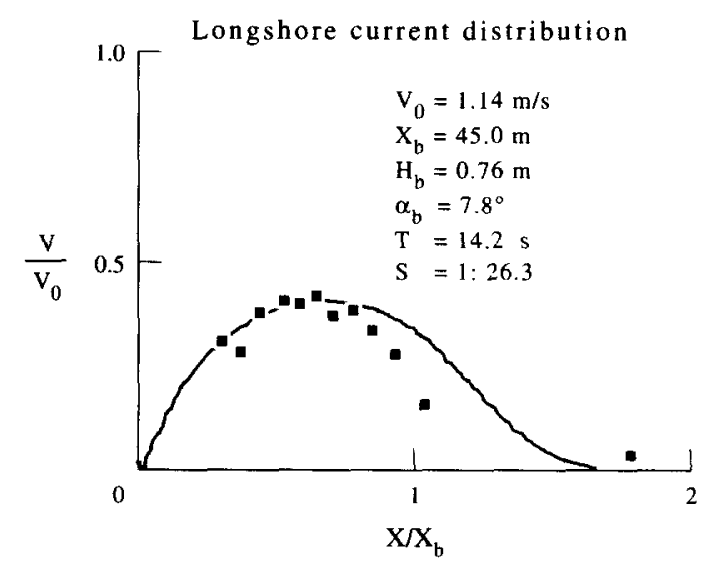

Figure 2. Print screen of computed longshore current distribution (-) for Thornton and Guza $(1986,1989)$ February 4 data $(\mathbf{\square})$. 
to other eddy viscosity coefficients, wave energy dissipation models, bottom shear stress theories, etc.

The present model for longshore current computations was combined with any of the known formulae for predicting sediment transport distribution. Some of them are described briefly in the Appendix.

\section{REFERENCES}

Bijker, E. W., 1967, Some considerations about scales for coastal models with movable bed: Publ. No. 50, Delft Hydraulics Laboratory, Delft, The Netherlands, $147 \mathrm{p}$.

Deguchi, I., Sawaragi, T., and Ono, M., 1992, Longshore current and lateral mixing in the surf zone (abst.): Proc. 23rd Coastal Engrg. Conf., A.S.C.E. (Venice, Italy), Book of Abstracts, Paper No. 172, p. 353-354.

Dingler, J. R., and Inman, B. L., 1976, Wave-formated ripples in nearshore sands: Proc. 15th Coastal Engrg. Conf., A.S.C.E. (Honolulu, Hawaii), p. 2109-2126.

Gable, C. G., ed., 1981, Report on data from the Nearshore Sediment Transport Study experiment on Leadbetter Beach, Santa Barbara, California, January-February 1980: IMR Ref. 80-5, Univ. California, Inst. Marine Resources, La Jolla, California, 314 p.

Jonsson, I. G., 1980, A new approach to oscillatory, rough turbulent boundary layers: Ocean Engrg., v. 7, no. 1, p. $109-152$.

Larson, M., and Kraus, N. C., 1989, SBEACH: numerical model for simulating storm-induced beach change: Rept 1, U.S. Army Coastal Eng. Res. Center, Washington, D.C. Tech. Rept. CERC-89-9, 255 p.

Mei, C. C., 1983, The applied dynamics of ocean surface waves: John Wiley \& Sons, Inc. New York, Ch. 10, p. 451-503.

Nielsen, P., 1981, Dynamics and geometry of wave generated ripples: Jour. Geophys. Res., v. 86, no. C7, p. 6467-6472.

Nielsen, P., 1985, A short manual of coastal bottom boundary layers and sediment transport: Public Works Dept., Tech. Memo. 85/1, N.S.W., 56 p.

Nishimura, H., 1988, Computation of nearshore current, in Horikawa, K., ed., Nearshore dynamics and coastal processes: Univ. Tokyo Press, Tokyo, Japan, p. 271-291.

Svendsen, I. A., 1987, Analysis of surf zone turbulence: Jour. Geophys. Res., v. 92, no. C5, p. 5115-5124.

Swart, D. H., 1976, Predictive equations regarding coastal transport: Proc. Coastal Engrg. Conf., A.S.C.E. (Honolulu, Hawaii), p. 1113-1132.

Thornton, E. B., and Guza, R. T., 1986, Surf zone longshore currents and random waves: Field data and models: Jour. Phys. Oceanography, v. 16, no. 7, p. 1165-1178.

Thornton, E. B., and Guza, R. T., 1989, Models for surf zone dynamics, in Seymour, R. J., ed., Nearshore sediment transport: Plenum Press, New York, p. 337-369.

Thornton, E. B., Wu, C. S., and Guza, R. T., 1984, Breaking design criteria: Proc. 19th Coastal Engrg. Conf. A.S.C.E. (Houston, Texas), p. 31-41.

U.S. Army Corps of Engineers, 1984, Shore Protection Manual: Wtrwy. Expr. Station, Vicksburg, Mississippi, v. 1, Ch. 4, p. $89-99$.

Van Rijn, L. C., 1989, Sediment transport by currents and waves: Handbook, Rept. H 461, Delft Hydraulics, Delft, The Netherlands, Ch. 2, p. 15-19 and Ch. 6, p. 15-21.

Visser, P. J., 1984, A mathematical model of uniform longshore currents and the comparison with laboratory data: Rept. No. 84-2, Dept. Civ. Engrg., Delft Univ. Tech., Delft, The Netherlands, $151 \mathrm{p}$.

Watanabe, A., 1992, Total rate and cross-shore distribution of longshore sand transport (abst.): Proc. 23rd Coastal Engrg. Conf., A.S.C.E. (Venice, Italy), Book of Abstracts, Paper No. 297, p. 619-620.
Wu, C. S., Thornton, E. B., and Guza, R. T., 1985, Waves and longshore currents: Comparison of a numerical model with field data: Jour. Geophys. Res., v. 90, no. C3, p. 4951-4958.

\section{APPENDIX}

\section{Sediment Transport Formulae}

Because details on the applied formulae are given in the original papers, the formulae are described only briefly in this Appendix.

\section{Adapted Engelund-Hansen Formula}

The formula for the total sediment transport $q_{\mathrm{T}}$ of the adapted Engelund-Hansen method is

$$
q_{\mathrm{T}}=V \frac{0.05 C_{\mathrm{h}} \tau_{\mathrm{T}}^{2}}{\rho^{2} \boldsymbol{g}^{5 / 2} \Delta^{2} D}
$$

where

$$
\begin{aligned}
\tau_{\mathrm{r}} & =\frac{1}{8} \rho F V^{2}\left[1+\frac{1}{2}\left(\xi \frac{u_{\mathrm{m}}}{V}\right)^{2}\right], \\
C_{\mathrm{h}}^{2} & =\frac{8 g}{F} \text { and } \Delta=s-1 .
\end{aligned}
$$

Bijker Formula

Bijker (1967) suggested to use the Kalinske-Frijlink formula for bedload computation

$$
q_{\mathrm{b}}=5 D \frac{V}{C_{\mathrm{h}}} \boldsymbol{g}^{1 / 2} \exp \left[\frac{-0.27 \Delta D \rho g}{\mu \tau_{\mathrm{r}}}\right],
$$

where $\mu=\left(C_{\mathrm{h}} / C_{90}\right)^{1.5}, C_{90}=18 \log (12 d) / D_{90}$. Bijker (1967) used the Einstein expression for suspended load. Swart (1976) proposed a modification of the procedure for calculations of suspended load. He used the following expression

$$
c=c_{a}\left(\frac{z}{a}\right)^{-\mathrm{b}},
$$

where $c$ is the sediment concentration at height $z, c_{a}$ the concentration at a reference height $a$ and

$$
b=1.05 Z^{0.96}\left[\frac{a}{d}\right]^{0.013 Z},
$$

with $Z=w_{\mathrm{s}} / 0.4 V_{*, \mathrm{r}}, V_{*, \mathrm{r}}=\left(\tau_{\mathrm{r}} / \rho\right)^{1 / 2}$ and $w_{\mathrm{s}}$ the sediment fall velocity.

The bedload is assumed to take place in a layer with thickness $a=r$ above the bed. From Bijker (1967)

$$
c_{a}=\frac{q_{\mathrm{b}}}{6.35 V_{*} r},
$$

so the suspended load becomes

$$
q_{\mathrm{s}}=\frac{\mathrm{q}_{b}}{6.35(1-b)}\left[\left(\frac{d}{r}\right)^{1-b}-1\right] \frac{V}{V_{*}},
$$

where $V_{*}=[1 / 8 F]^{1 / 2} V$. The total load is $q_{\mathrm{T}}=q_{\mathrm{b}}+q_{\mathrm{s}}$.

\section{Watanabe Formula}

The sediment transport formula proposed by Watanabe (1992) is

$$
q_{\mathrm{T}}=A_{\mathrm{c}}\left[\frac{\left(\tau-\tau_{\mathrm{cr}}\right) V}{\rho g}\right],
$$

where $A_{\mathrm{c}}$ is a dimensionless coefficient of order $2, \tau$ the maximum value of bottom friction under the combined action of waves and longshore current with the roughness length equal to the grain diameter, $\tau_{\mathrm{cr}}=\left(\rho_{\mathrm{s}}-\rho\right) \mathrm{g} D \theta_{\mathrm{cr}}$ the critical shear stress for the onset of general sand movement and $\theta_{\mathrm{cr}}$ the Shields parameter. Here $\tau_{\mathrm{r}}$ is used instead of $\tau$. 
CERC Formula

The CERC formula is an integral method which relates the total sediment transport across the surf zone with the longshore component of the wave energy flux at the breaker line (U.S. Army Corps of Engineers, 1984)

$$
Q_{\mathrm{T}}=K \frac{P_{\mathrm{lb}}}{\left(\rho_{\mathrm{x}}-\rho\right) g a^{\prime}},
$$

where $K$ is a dimensionless constant, $a^{\prime}=0.65$ the sand porosity and $P_{\mathrm{bb}}=E_{\mathrm{b}} C_{\mathrm{b}} \sin \alpha_{\mathrm{b}} \cos \alpha_{\mathrm{b}}$ the longshore component of the wave energy flux. The subscript $b$ indicates that all evaluations are to be made at the breaker line. A value of $K=0.77$ must be used if the computation of $P_{1 b}$ is based on the $H_{\text {r.m.s. }}$ wave height. For reducing the wave height to the breaker line is used the usual breaking criterion for spilling breaking waves, $\gamma=\mathbf{0 . 7 8}$.

\title{
Program Listing
}

\begin{abstract}
A QuickBASIC 4.50 program to compute longshore currents and the associated sediment transport
\end{abstract}

S -Beach slope (non-dimensional),

HO1 - Wave height to an arbitrary depth (meters);

HB -Wave height at the breaker line (meters),

TA -Angle that wave front makes with the shore line (degree);

T -Wave pertod (seconds),

DO1 -Depth of the wave measurements (meters),

D50 -Mean sediment diameter (millimeters);

D90 -Particle diameter such that $10 \%$ by weight exceeded in size (millimeters),

RSED-Sediment density (kilogram per cubic meter).

$V(I)$-Nondimensional current velocity

CLS

LOCATE 12, 15: INPUT "DO YOu want to see the instructions-(Y or N)", P\$ IF $P \$=" N "$ OR P\$ $=" n "$ GOTO 5

CLS : LOCATE 4, 25: PRINT "Input parameters:"

LOCATE 8,10

PRINT "A-Significant wave height or root-mean square wave height (m)." LOCATE 9,10

PRINT "B-Angle that wave front makes with the shore line (degree)."

LOCATE 10, 10: PRINT "C-Wave period (s)."

LOCATE 11, 10: PRINT -D-Beach slope."

LOCATE 12, 10: PRINT -E-Mean sediment diameter, D50 (mm)."

LOCATE 13,10

PRINT "F-Particle diameter such that $10 \%$ by weight exceeded"

LOCATE 14, 10:

PRINT " in size, D90 (mm). It is not strictly necessary for the"

LOCATE 15, 10: PRINT " program to be run."

LOCATE 16, 10: PRINT "G-Sediment density $(\mathrm{kg} / \mathrm{m} 3)$."

LOCATE 17,10

PRINT "H-Depth of wave measurements (m). It is necessary only when the" LOCATE 18, 10: PRINT "input conditions are not at the breaker line." LOCATE 25, 10: INPUT "Press ENTER to continue"; P\$

5 DIM $H(241), \operatorname{ALF}(241), F C(241), F W(241), \operatorname{OM}(241), D(241), A H(241)$

DIM W(241), U(241), V(241), V1(241), QB(241), QW(241), QH(241), R(241)

10 CLS : LOCATE 8, 15: PRINT "Wave height parameter"

LOCATE 11, 10: PRINT - Significant wave height ....... (1) "

LOCATE 12, 10: PRINT "Root-mean square wave height ... (2).

LOCATE 13, 10: INPUT “

LOCATE 12, 10: INPOT "Are conditions at the breaker line-(Y or N)", C\$

CLS : LOCATE 12, 15: INPUT "Beach slope", $S$

CLS : LOCATE 12, 15: INPUT Wave height", HO1

CIS : LOCATE 12, 15: INPUT "Wave angle", TA

CLS : LOCATE 12, 15: INPUT wave perlod", T

CLS : LOCATE 12, 15: INPUT Mean sediment diameter", D50

CLS : LOCATE 12, 12

INPUT Is the sediment diameter D90 avallable-(Y or $N) \cdots, P 1 \$$

CLS : IF P1\$ = "Y" OR PIS = "Y" THEN LOCATE 12, 20 : INPUT "D90", D90

CLS : LOCATE 12, 15: INPUT "sediment density", RSED

IF C\$ = "Y" OR C\$ = "Y" GOTO 15

CLS : LOCATE 12, 15 : INPUT "Depth of wave measurements", DO1 
15 IF D\$ = " I" THEN HO1 $=$ HO1 / $(2 \wedge .5)$

$\mathrm{D} 50=\mathrm{D} 50 / 1000: \mathrm{D} 90=\mathrm{D} 90 / 1000$

T01 $=$ TA *ATN (1) / 45

IF C\$ = "Y" OR C\$ = "Y" THEN HB $=$ HOI: TB $=$ T01

LO $=9.8 *\left(T^{\wedge} 2\right) /(8 * \operatorname{ATN}(1)): C O=L O / T$

$\mathrm{AA1}=.603+2.147 * \mathrm{~S}$

$\mathrm{BB} 1=30.685 * \mathrm{~s}-5.192$

IF C\$ = "N" OR C\$ = "n" GOTO 20

$\mathrm{HO}=((2 \wedge .5) * \mathrm{HB} *($ LO $\wedge-.24) / .53) \wedge(1 / .76)$

$\mathrm{MO}=\mathrm{AA1}+\mathrm{BBI} \star(\mathrm{HO} / \mathrm{LO}): \mathrm{MU}=\mathrm{MU} /(2 \wedge .5):$ HO $=\mathrm{HO} /(2 \wedge .5)$

$\mathrm{PB}=\mathrm{HB} / \mathrm{MU}$

$\mathrm{CB}=((9.8 * \mathrm{~PB}) \wedge .5) *(1-\mathrm{PB} / \mathrm{LO})$

GOTO 30

Deep water wave condition computation

20 IF DOI >= LO / 2 THEN TO = TO1: HO = HOL: GOTO 25

$\mathrm{CO1}=((9.8 * \mathrm{DO1}) \wedge .5) *(1-\mathrm{DO1} / \mathrm{LO})$

IF DOI / LO > .36 THEN COI = CO

$\mathrm{LO1}=\mathrm{CO1} * \mathrm{~T}$

$A L F 5=\operatorname{SIN}(T 01) * \mathrm{CO} / \mathrm{COI}$

TO $=\operatorname{ATN}(\operatorname{ALF5} /((1-\operatorname{ALF5} \wedge 2) \wedge .5))$

$\mathrm{KK}=8 * \operatorname{ATN}(1) * \mathrm{DO1} / \mathrm{LO1}$

$\mathrm{SH} 1=2.7182818 \# \wedge(2 * \mathrm{KK}): \mathrm{SH} 2=2.7182818 \# \wedge-(2 * \mathrm{KK})$

$\mathrm{SH}=(\mathrm{SH} 1-\mathrm{SH} 2) / 2: \mathrm{GX}=1+2 * \mathrm{KK} / \mathrm{SH}: \mathrm{CGO} 1=.5 * \mathrm{CO} 1 * \mathrm{GX}$

HO $\left.=\mathrm{HO} *((2 * \operatorname{CGO1} * \operatorname{COS}(\mathrm{TO} 1) /(\mathrm{CO} * \cos (\mathrm{T} 0))))^{*} .5\right)$

Breaking wave computation

$25 \mathrm{MO}=\mathrm{AAI} /(2 \wedge .5)+\mathrm{BBI} *(\mathrm{HO} / \mathrm{LO})$

$\mathrm{HB}=\mathrm{HO}$

DO

$\mathrm{HB} 1=\mathrm{HB}$

$\mathrm{PB}=\mathrm{HB} / \mathrm{MU}$

$\mathrm{CB}=((9.8 * \mathrm{~PB}) \wedge .5) *(1-\mathrm{PB} / \mathrm{LO})$

$A L F 7=\operatorname{SIN}(\mathrm{TO}) * \mathrm{CB} / \mathrm{CO}$

$\mathrm{TB}=\mathrm{ATT}(\mathrm{ALF7} /((1-\mathrm{ALF7} \wedge 2) \wedge .5))$

$\mathrm{HB}=\mathrm{HO} *((\mathrm{CO} * \operatorname{COS}(\mathrm{TO}) /(2 * \mathrm{CB} * \cos (\mathrm{TB}))) \wedge .5)$

LOOP WHILE ABS (HBI - HB) $>.001$

$30 \mathrm{LP}=3 * \mathrm{HB}$

$\mathrm{XS}=3 *(\mathrm{MU} \wedge 2) *(\mathrm{~PB} / \mathrm{S}-3 * \mathrm{HB}) / 8$

$X B=P B / S+X S$

$\mathbf{X P}=\mathbf{X B}-\mathbf{L P}$

$\mathrm{XS}=\mathrm{XS} / \mathrm{XB}: \mathrm{P}=\mathrm{XP} / \mathrm{XB}$

Plunge line search

$D X=1 / 80$

$\mathbf{J}=0$

DO

PP $=$ P

$P P=P P-D X: J=J+1$

LOOP UNTIL PP $<=$ DX

$\mathbf{P}=\mathbf{J} * \mathbf{D X}$

$I P=J+1$

$\mathrm{J}=0:$ PP $=0$

CGI = CGO1: TI = T01: CI = CO1: HI $=$ HO1: EI $=9.8 *\left(H_{01} \wedge 2\right) / 8$

$\mathrm{EB}=9.8 *(\mathrm{HB} \wedge 2) / 8: \mathrm{EO}=9.8 *(\mathrm{HO} i 2) / 8$

IF CS = "Y" OR C\$ = "Y" THEN $\mathrm{EI}=\mathrm{EB}$; TI $=\mathrm{TB}:$ CGI $=\mathrm{CB}$

IF C\$ = "Y" OR C\$ = "Y" THEN HI = HB : CI $=\mathrm{CB}$

IF HO1 $=$ HO THEN EI $=$ EO: TI $=$ TO: CGI $=$ CO $/ 2:$ CI $=$ CO: HI = HO

$\mathrm{DB}=2.5 * \mathrm{EI} * \mathrm{CGI} * \cos (\mathrm{TI}) /(\mathrm{P} * \mathrm{XB})$

$M=3$

$\mathrm{B} 1=3 /(M *(((1-X S / P) * S) \wedge 2)): B 2=3 /((S \wedge 2) * M)$

$\mathrm{R} 1=-.5+(.25+\mathrm{B} 1) \wedge .5: \mathrm{R} 2=-.5-(.25+\mathrm{B} 2) \wedge .5$

$A 12=R 2-R 1 *(1-x S ; P)$

$A 1=((1-X S / P) * 1.5-R 2) *(P \wedge-R 1) / A 12$

$\mathrm{A} 2=((\mathrm{P}-\mathrm{XS}) \wedge(1-\mathrm{R} 2)) *((1.5-\mathrm{R} 1) / \mathrm{P}) / \mathrm{A} 12$ 


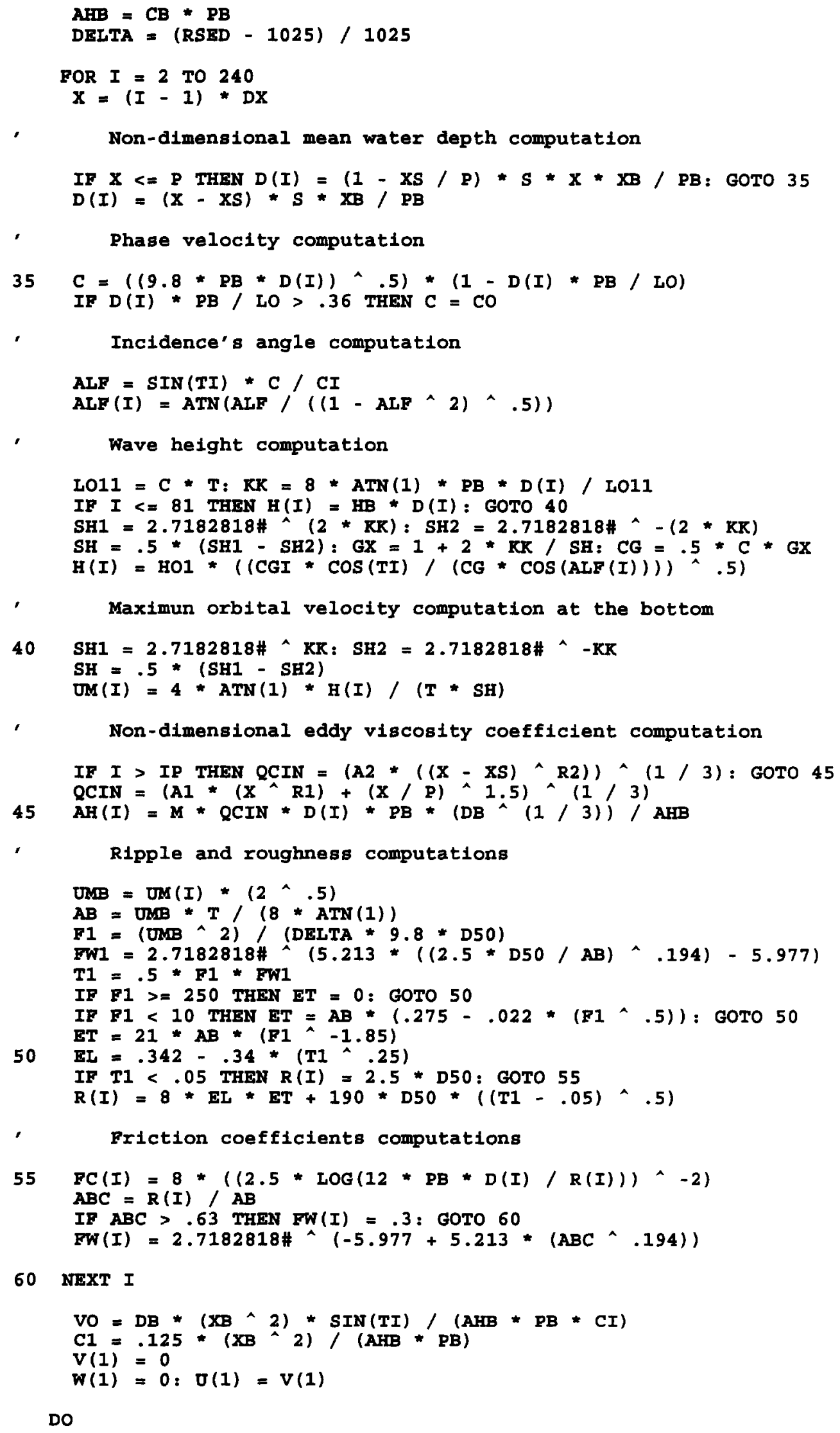

60 NEXT I

$\mathrm{VO}=\mathrm{DB} *(\mathrm{XB} \wedge 2) * \operatorname{SIN}(\mathrm{TI}) /(\mathrm{AHB} * \mathrm{~PB} * \mathrm{CI})$

$\mathrm{C1}=.125 *(\mathrm{XB} \wedge 2) /(\mathrm{AHB} * \mathrm{~PB})$

$\mathrm{V}(1)=0$

$W(1)=0: \delta(1)=V(1)$

Do 


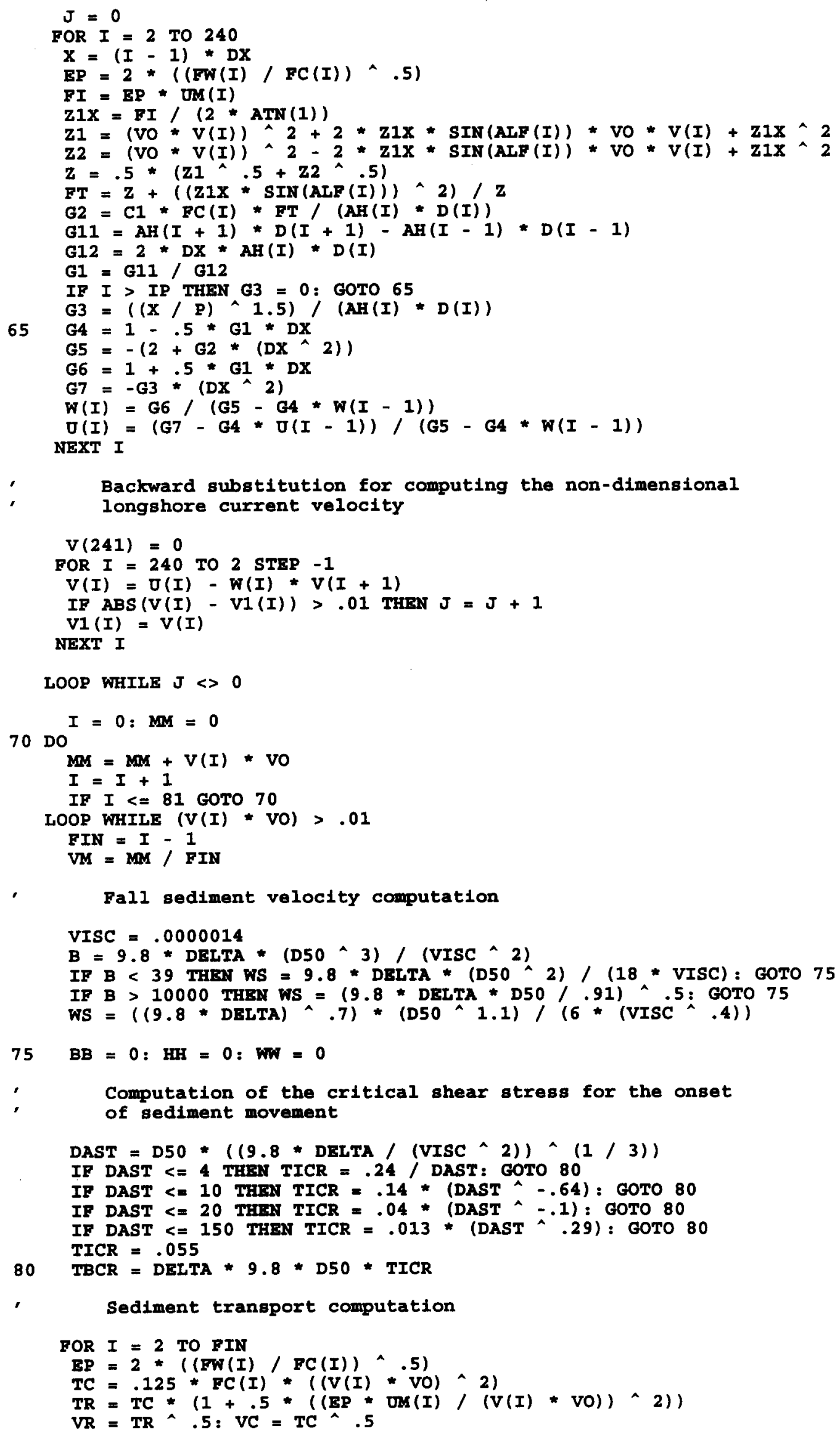


Bifker formula

$\mathrm{CHE}=(8 * 9.8 / \mathrm{FC}(I)) \wedge .5$

IF $\mathrm{P} 1 \$=" N "$ OR P1\$ = " $\mathrm{n}$ " GOTO 85

IF TR $<=$ TBCR GOTO 85

$\mathrm{B} 11=$ WS $/(.4 *$ VR $)$

$B 1=1.05 *(B 11 * .96) *((R(I) /(D(I) * B B)) \wedge(.013 * B 11))$
$B 12=1-B 1$

$\mathrm{Z1}=((\mathrm{D}(\mathrm{I}) * \mathrm{~PB} / \mathrm{R}(\mathrm{I})) \wedge \mathrm{B} 12)-1$

FC90 $=8 *((2.5 * \operatorname{LOG}(12 * D(I) * P B / D 90)) \wedge-2)$

$\mathrm{CH} 90=(8 * 9.8 / \mathrm{FC} 90) \wedge .5$

$\mathrm{NU}=(\mathrm{CHE} / \mathrm{CH} 9 \mathrm{O}) \wedge 1.5$

$\mathrm{QBB}=5 * \mathrm{D} 50 * \mathrm{VC}$

$Q B=Q B B *(2.7182818 \# \wedge-(.27 * 9.8 *$ DELTA * D50/(NU * TR ) ) )

$Q S=Q B * 21 * V(I) * V O /(6.35 * B 12 * V C)$

$Q B(I)=Q B+Q S$

IF $Q B(I)>Q B(I-1)$ THEN QBNAX $=Q B(I)$

$B B=B B+Q B(I)$

Watanabe formula

IF TR $<=$ TBCR GOTO 90

$Q T=2 *(T R-T B C R) * V(I) * V O / 9.8$

$Q W(I)=Q T$

IF $Q W(I)>Q W(I-1)$ THEN WAMAX $=Q W(I)$

$W W=W W+O W(I)$

Adapted Engelund-Hansen formula

$\mathrm{QH} 1=((9.8 * \mathrm{DELTA}) \wedge 2) * \mathrm{D} 5 \mathrm{2} *(9.8 * .5)$

$\mathrm{QH}(I)=.05 * \mathrm{CHE} *(\mathrm{TR} \wedge 2) * \mathrm{~V}(\mathrm{I}) * \mathrm{VO} / \mathrm{QHI}$

IF $Q H(I)>Q H(I-1)$ THEN QEMAX $=Q H(I)$

$\mathrm{HH}=\mathrm{HH}+\mathrm{OH}(I)$

NEXT I

CERC Formula

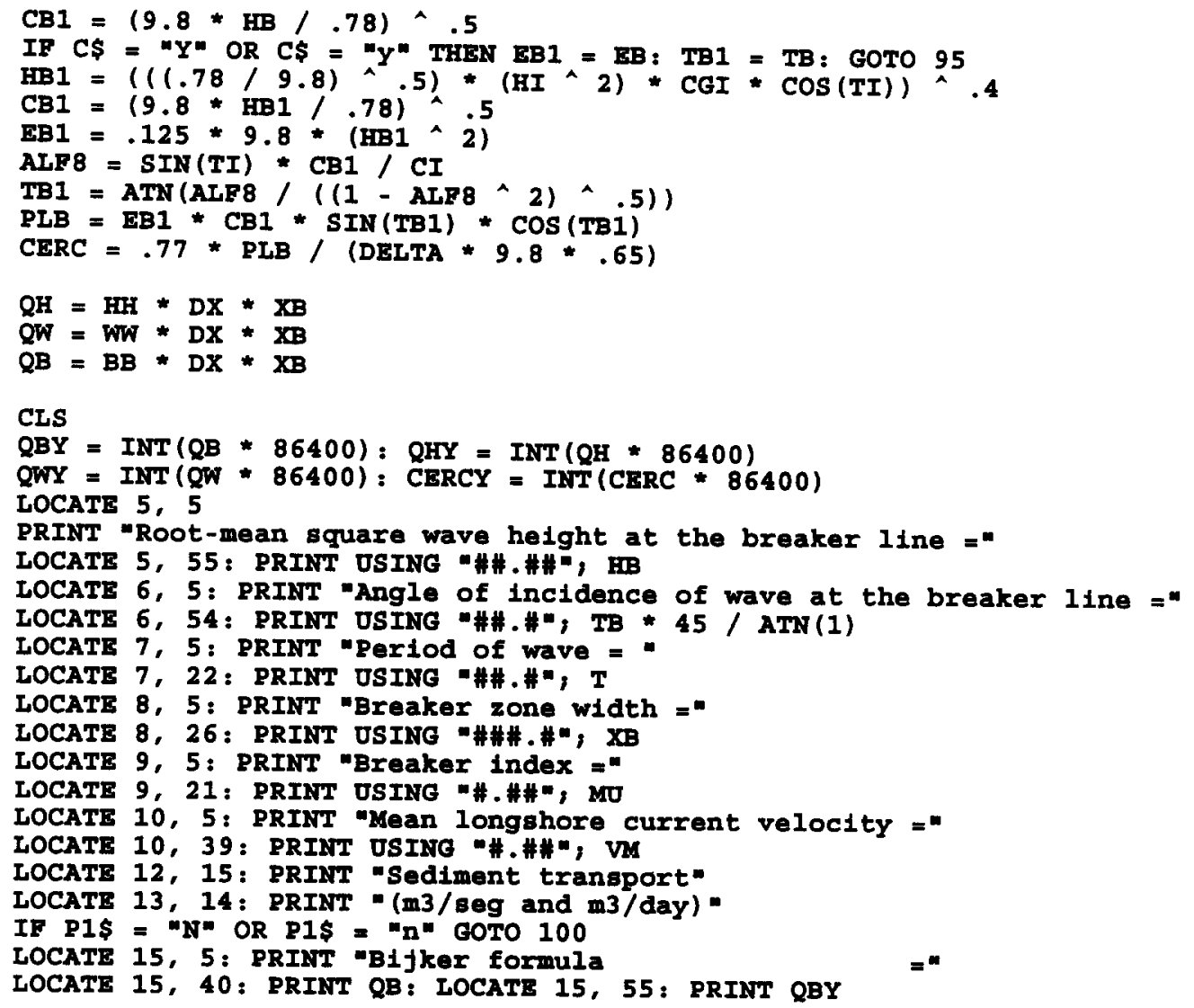


100 LOCATE 16, 5: PRINT "Adapted Engelund-Hansen formula =" LOCATE 16, 40: PRINT QH: LOCATE 16, 55: PRINT QHY LOCATE 17, 5: PRINT "Watanabe formula LOCATE 17, 40: PRINT QW: LOCATE 17, 55: PRINT OWY LOCATE 18, 5: PRINT - CERC formula LOCATE 18, 40: PRINT CERC: LOCATE 18, 55: PRINT CERCY

LOCATE 25, 5: INPUT -Paper output-(Y or N) *; YY\$

$\mathrm{TB}=\mathrm{TB} * 45 / \mathrm{ATN}(1)$

IF YY\$ = "N" OR YY\$ = "n" GOTO 110

IPRINT TAB (10); "Breaking wave height = "; USING "\#.\#\#", HB

LPRINT TAB (10), "Angle of Incidence at breaking = ", USING "\#.\#", TB

LPRINT TAB (10); "Period of wave = "; USING "\#\#.\#", T

IPRINT TAB (10); "Breaker zone width = "; USING "\#\#\#.\#"; XB

LPRINT TAB (10); "Breaker index = ", USING "\#.\#\#", MU

LPRINT TAB (10); "Mean longshore current velocity = "; USING "\#.\#\#", VM IPRINT

LPRINT TAB (30); "Sediment transport"

LPRINT TAB (29); " (m3/seg and m3/day)"

I.PRINT

IF P1\$ = "N= OR P1\$ = "n" GOTO 105

IPRINT TAB (10); "Bijker formula="; TAB (45); $Q B ; T A B(60) ; Q B Y$

105 LPRINT TAB (10); "Engelund-Hansen formula="; TAB (45); $Q H$; TAB (60); $Q H Y$

LPRINT TAB (10); "Watanabe formula="; TAB (45); $Q W ; T A B(60) ; Q W Y$

LPRINT TAB (10); "CERC formula $="$;AB (45); CERC; TAB (60); CERCY

110 CLS

LOCATE 12, 15: PRINT "Do you want to see the longshore current"

LOCATE 13,15

INPUT "and sediment transport distributions-( $Y$ or $N) "$, P\$

IF PS = "N" OR P\$ = "n" GOTO 150

SCREEN 11

115 CLS : LOCATE 12, 8: PRINT "Longshore current distribution...... (1)* LOCATE 13, 8: PRINT "Sediment transport distribution...... (2)"

LOCATE 14, 44: INPUT, A2

CIS : IF A2 = 1 GOTO 125

IF P1\$ = "N" OR P1\$ = "n" GOTO 120

LOCATE 10, 15: PRINT "Bijker formula.............. (1) "

120 LOCATE 11, 15: PRINT "Watanabe formula............... (2)" LOCATE 12, 15: PRINT mAdapted Engelund-Hansen formula.. (3) " LOCATE 13, 47: INPUT ; A3

125 CLS

LINE $(100,350)-(500,350)$ : IINE $(100,350)-(100,360)$

LINE $(500,350)-(500,360)$ : LINE $(300,350)-(300,360)$

LINE $(200,350)-(200,355)$ : LINE $(400,350)-(400,350)$

LOCATE 24, 12.5: PRINT $0.0 "$ : LOCATE 24, 62: PRINT "2.0"

LOCATE 24, 37.25: PRINT "1.0": LOCATE 25.4, 36.5: PRINT "X/ Xb"

IF $A 2=1$ THEN X\$ = "V": Y\$ = "..":Z\$ = "VO"

IF A2 = 1 THEN LOCATE 9, 53: PRINT "Vo = ", USING "\#.\#\#"; vo

IF A2 = 1 THEN LOCATE 9, 65: PRINT mm/s": GOTO 130

LOCATE 4, 20: PRINT "Sediment transport distribution"

$X \$=" q^{\prime \prime}: X \$="-. ": Z \$="$ qo"

IF $A 3=1$ THEN Q01 $=$ QBMAX

IF $A 3=2$ THEN Q01 = WAMAX

IF $A 3=3$ THEN QO1 = QEMAX

LOCATE 9, 53: PRINT "qO = ", USING "\#.\#\#\#\#", 201

LOCATE 9, 65: PRINT "m": LOCATE 8.5, 65.5: PRINT 2

LOCATE 9, 67: PRINT */s"

130 IF A2 = 1 THEN LOCATE 4, 20: PRINT "Longshore current distribution" IF $A 2=1$ GOTO 135

IF A3 = 1 THEN LOCATE 5, 27: PRINT "BIfker formula"

IF $A 3=2$ THEN LOCATE 5, 26: PRINT "Watanabe formula"

IF A3 = 3 THEN LOCATE 5, 20: PRINT "Adapted Engelund-Hansen formula" 
135 LOCATE 10, 53: PRINT "Xb ="; USING "\#\#\#\#"; XB

LOCATE 10, 65: PRINT "m"

LOCATE 14.5, 4: PRINT X\$: LOCATE 14.501, 3: PRINT Y\$

LOCATE $15.5,3.2$ : PRINT $\mathrm{z} \$$

LINE $(100,350)-(100,100)$ : LINE $(100,350)-(90,350)$

LINE $(100,100)-(90,100):$ LINE $(100,225)-(90,225)$

LINE $(100,287.5)-(95,287.5)$ : LINE $(100,162.5)-(95,162.5)$

LOCATE 22.51, 8.5: PRINT "0.0": LOCATE 6.51, 8.5: PRINT "1.0"

LOCATE $14.51,8.5$ : PRINT 0.5 "

IOCATE 11, 53: PRINT "Hb =", OSING "\#\#.\#\#; HB

LOCATE 11, 65: PRINT "m"

LOCATE 12, 53: PRINT " $\alpha b="$, USING "\#\#.\#", TB

LOCATE 12, 65: PRINT $\cdots "$

LOCATE 13, 53: PRINT "T ="; USING "\#\#.\#"; T

LOCATE 13, 65: PRINT " $\mathrm{g}$ "

LOCATE 14, 53: PRINT "S = 1:"; USING "\#\#\#.\#"; $1 / \mathrm{S}$

IF $A 2=1$ THEN LINE $(405,111)-(548,111):$ LINE $(405,111)-(405,235)$

IF $A 2=1$ THEN IINE $(548,111)-(548,235)$

IF A2 = 1 THEN LINE $(405,235)-(548,235)$ : GOTO 140

IINE $(405,108)-(560,108)$ : LINE $(405,108)-(405,235)$

LINE $(560,108)-(560,235)$ : LINE $(405,235)-(560,235)$

$140 \mathrm{~V} 1(1)=350$

FOR $I=2$ TO FIN

IF $A 2=1$ THEN $A 1=V(I)$

IF $A 3=1$ THEN $A 1=Q B(I) / Q B M A X$

IF $A 3=2$ THEN $A 1=Q W(I) /$ WAMAX

IF $A 3=3$ THEN $A 1=Q H(I) /$ QEMAX

IF I > 161 GOTO 145

$X=100+200 *(I-1) / 80$

$X 1=100+200 *(I-2) / 80$

$\mathrm{VI}(\mathrm{I})=350-250 * \mathrm{Al}$

LINE (X1, V1 $(I-1))-(X, V 1(I))$

NEXT I

145 LOCATE 30, 10: INPUT "More graphics-(Y or N) ", P\$

IF $P \$=" Y " O R$ P\$ $=" Y "$ THEN A2 $=0: A 3=0$ : GOTO 115

$150 A 2=0: A 3=0$

CLS : SCREEN 0

LOCATE 12, 15: INPUT More calculations-(Y or N)", XX\$

IF XXS = "Y" OR XXS = "Y" THEN CLEAR: GOTO 10

CLS : END 